\title{
Evaluation of Characteristics of Activated Carbon from Rice Husk Impregnated with Zinc Chloride and Phosphoric Acid
}

\author{
Mohamed Ahiduzzaman ${ }^{1, ~ *, ~ A b u l ~ K . ~ M . ~ S a d r u l ~ I s l a m ~}{ }^{2}$ \\ ${ }^{1}$ Department of Agro-processing, Bangabandhu Sheikh Mujibur Rahman Agricultural University, Gazipur, Bangladesh \\ ${ }^{2}$ Department of Mechanical and Chemical Engineering, Islamic University of Technology, Gazipur, Bangladesh
}

Email address:

ahid72@yahoo.com (M. Ahiduzzaman)

${ }^{*}$ Corresponding author

\section{To cite this article:}

Mohamed Ahiduzzaman, Abul K. M. Sadrul Islam. Evaluation of Characteristics of Activated Carbon from Rice Husk Impregnated with Zinc Chloride and Phosphoric Acid. American Journal of Physical Chemistry. Vol. 5, No. 5, 2016, pp. 94-98.

doi: 10.11648/j.ajpc.20160505.12

Received: October 5, 2016; Accepted: October 14, 2016; Published: November 10, 2016

\begin{abstract}
Activated carbon is essential in adsorption process of different dye and metals from waste streams. The molecular size of different species is different. So they could have some restriction to move into the pore in activated carbons smaller than their molecule size. In this regards a study is conducted to evaluate the adsorption characteristics of zinc chloride and phosphoric acid impregnated activated carbon. Methylene blue (MB) and nitrogen having two distinct molecular sizes are adsorbed to evaluate the adsorption characteristics of the activated carbons. Nitrogen molecules have access into smaller pores compared to MB molecules. Nitrogen adsorption test shows higher specific surface area compared to MB adsorption test. In methylene adsorption test, phosphoric acid impregnated activated carbon shows higher specific surface area $\left(646 \mathrm{~m}^{2} \mathrm{~g}^{-1}\right)$ compared to that of zinc chloride impregnated activated carbon $\left(599 \mathrm{~m}^{2} \mathrm{~g}^{-1}\right)$. In contrast zinc chloride shows higher specific surface area $\left(927 \mathrm{~m}^{2} \mathrm{~g}^{-1}\right)$ compared to that of phosphoric acid impregnated activated carbon $\left(718 \mathrm{~m}^{2} \mathrm{~g}^{-1}\right)$ in liquid nitrogen adsorption test. This happened because zinc chloride could develop smaller size pore in higher degree compared phosphoric acid during activation process. Results show that development of pore size is affected by two different agents. MB and nitrogen adsorption test reveals that zinc chloride activated material produced more number of small pores compared to phosphoric acid activated material. From this study it is concluded that the desired size of pores in activated carbon could be achieved for adsorption of species with specific molecular diameter by varying the type of activation agents.
\end{abstract}

Keywords: Activated Carbon, BET Surface Area, Activation Agent, SEM Image, Contact Time Study

\section{Introduction}

The pollution control and environmental safety have got global attention and has opened new window for development in the adsorption process technology. In many industrial processes, for example, textile, washing, printing release pollutant into stream. Thus effluent treatment plant, a mandatory measure to recover them or reduce their concentrations in effluent streams, is employed due to environmental concerns, where adsorption method is used as it is one of the most effective and versatile methods. Activated carbons, are frequently used as adsorbent, remove a numerous species from waste stream as it has an excellent adsorption capacity, which is related to a large specific surface area and porousness. Several investigations have been found using activated carbon for removal of various species [1-13]. Despite its prolific use, activated carbons in water and wastewater industries, commercial activated carbons remain an expensive material. This has led to a search for low-cost, easily available materials as alternative adsorbent materials. Proper utilization of agro industrial byproduct is very much important for economic development. A wide variety of activated carbons have been prepared from agricultural waste such as coconut shells, cotton stalk, sugarcane bagasse, coir pith, straw [14-18] and also from non-renewable materials like coal, wood, and peat [19-23]. 
Activated carbons adsorb a wide variety of substances including different types of dyes and heavy metals. It is the porous structure and chemical nature of the surface of carbons that govern this property, both of which are related to the crystalline composition. Although the microcrystalline structure is dependent on the raw material, impurities and conditions of production, the basic structural unit is similar to that of graphite.

Pore size is an important parameter for quality of activated carbon. Based on the effective radii and mechanism of gas adsorption, pores are classified to be macro-pores $(>50 \mathrm{~nm})$, meso-pores (2 to $50 \mathrm{~nm}$ ) and micro-pores $(<2 \mathrm{~nm})[24,25]$. The main role of macro-pores in adsorption is to act as transport arteries that allow the meso- and micro-pores to become accessible to particles of the adsorbate. Meso-pores contribute significantly to the adsorption process and also provide the main transport arteries for the adsorbate. Adsorption occurs in micro-pores through the mechanism of volume filling. The energy of adsorption in micro-pores is much higher, resulting in a large increase in adsorption capacity for small equilibrium pressures of adsorbate. The molecular sizes of different pollutant species are different. Therefore, activated carbon having smaller pores are not able to adsorp pollutants having larger diameter. Hence, there is knowledge gap of developing different pore sized activated carbon warrants conducting study on variation of pore development in activated by various methods.

In this study, we investigated the effect of activation agent on variation in pore size development in activated carbon; and evaluated them by adsorbing two distinct adsorbents having differences in molecular size.

\section{Materials and Methods}

\subsection{Preparation of Activated Carbon with Zinc Chloride and Phosphoric Acid Activation}

Activated carbon investigated in this study prepared from rice husk. Rice husk char was prepared as described in [32, 33]. Two grams ( $2 \mathrm{~g})$ of rice husk char was soaked in zinc chloride solution for $24 \mathrm{~h}$. Then the crucible was placed inside a muffle furnace to give a required heat treatment. After activation with zinc chloride, the samples were washed with $0.3(\mathrm{~N})$ hydrochloric acid solutions firstly and then washed with distilled water until the $\mathrm{pH}$ value reached 7.0. After washing the samples are dried in an oven at $105^{\circ} \mathrm{C}$ for $24 \mathrm{~h}$. Then the dried samples are preserved in desiccators to avoid further absorption of moisture. Similar procedure was followed to prepare phosphoric acid activated carbon. The ratio of rice husk char and activation agents were fixed after several trials. The detail methods are described in [32, 33].

\subsection{Comparative Evaluation of Zinc Chloride and Phosphoric Acid Activated Carbon}

The activated carbon samples were evaluated three ways: i) Scanning electron microscopy (SEM) image analysis, ii) specific surface area analysis, and iii) kinetic study. SEM images show differences visually. Specific surface area was evaluated by two methods: i) methylene blue adsorption, and ii) liquid nitrogen adsorption. Methylene blue and liquid nitrogen have two distinct molecular surface area of $130 \AA^{2}$ and $16.2 \AA^{2}$, respectively. Liquid nitrogen has ability to occupy more acute pore level than methylene blue. Specific area measured by these two methods provide a comparison of pore developed in the prepared activated carbon samples with two different activation agents. Adsorption kinetic study was conducted to compare performance of two activated carbon samples. Different methods of performance studies are described in the following sub-sections.

\subsubsection{Specific Surface Area Measured by Methylene Blue Adsorption}

Specific surface area was calculated based on area occupied by one molecule of methylene blue. The occupied surface area by one molecule of methylene blue is considered to be $130 \AA^{2}$. Then the specific surface area is calculated by using the equation (1):

$$
S_{s}=\frac{q_{e} \times N \times A_{M B}}{W}
$$

Where, $\mathrm{S}_{\mathrm{s}}=$ specific surface area, $\mathrm{m}^{2} / \mathrm{g} ; \mathrm{q}_{\mathrm{e}}=$ amount of methylene blue adsorbed, $\mathrm{mg} / \mathrm{g} ; \mathrm{W}=319.86 \times 10^{3}$, molar weight of methylene blue, mg per mole; $\mathrm{N}=$ Avogadro's number $\left(6.02 \times 10^{23}\right.$ molecules per mole $) ; \mathrm{A}_{\mathrm{MB}}=$ area covered by one molecule of mehtylene blue $\left(130 \times 10^{-20} \mathrm{~m}^{2}\right)$.

\subsubsection{Specific Surface Area Measured by Liquid Nitrogen Adsorption}

In this method, specific surface area was measured based BET procedure. One form of the well-known BET equation [34] that describes the physical adsorption of gas upon a solid surface is as in equation (2):

$$
\frac{\frac{P}{P_{0}}}{V\left[1-\frac{P}{P_{0}}\right]}=\frac{1}{V_{m} C}+\left(\frac{C-1}{V_{m} C}\right)\left(\frac{P}{P_{0}}\right)
$$

Where,

$\mathrm{V}=$ the volume of gas adsorbed at STP, $\mathrm{cm}^{3} / \mathrm{g} ; \mathrm{P}=$ atmospheric pressure; $\mathrm{P}_{0}=$ the saturation pressure which is the vapor pressure of liquefied gas at the adsorbing temperature; $\mathrm{V}_{\mathrm{m}}=$ the volume of gas required to form an adsorbed monomolecular layer at STP, $\mathrm{cm}^{3} / \mathrm{g} ; \mathrm{C}=\mathrm{a}$ constant to the energy of adsorption.

The surface area $\mathrm{S}\left(\mathrm{m}^{2} / \mathrm{g}\right)$ of the sample giving the monolayer adsorbed gas volume $\mathrm{V}_{\mathrm{m}}$ at STP is then calculated from equation (3)

$$
S_{s}=\frac{V_{m} A_{V} N}{M}
$$

Where, $\quad \mathrm{N}=$ Avogadro's number $\left(6.023 \times 10^{23}\right)$ molecules/mole of gas at STP; $\mathrm{M}=$ molar volume of gas at 
STP $\left(22.414 \times 10^{3} \mathrm{~cm}^{3} /\right.$ mole $) ; A_{V}=$ the area of each adsorbed molecule of nitrogen gas $\left(16.2 \times 10^{-20} \mathrm{~m}^{2} /\right.$ molecule $)$

From equation (2) the value of $\mathrm{V}_{\mathrm{m}}$ is calculated as in equation (4).

$$
V_{m}=\frac{1}{(\text { slope }+ \text { int ercept })}
$$

By putting the value of $A_{V}, N$, and $M$ in equation (3) can be simplified as following equation (5).

$$
S=\frac{4.353}{(\text { slope }+ \text { int errept })}
$$

BET surface area measurement experiment was conducted by using Micromeritics equipment (Model: Pulsechemisorb 2705) at the laboratory of Chemical Engineering Department, Bangladesh University of Engineering and Technology, Dhaka. The equation (2) was plotted with reading from micromeritics equipment; slope and intercept were estimated from the plot; finally, the BET surface area was estimated from the equation (5).

\subsubsection{Contact Time Study}

To determine the equilibrium time a kinetic study was carried out. The time to reach equilibrium was determined by a series of measurements over the range of $30 \mathrm{~min}$ to $480 \mathrm{~min}$ at room temperature. Contact time study was investigated to examine the rate of adsorption of different types of activated carbon prepared in this study. Methylene blue solution of $5 \times 10^{-5} \mathrm{M}(16 \mathrm{mg} / \mathrm{L})$ concentration was used in this investigation. $100 \mathrm{ml}$ of methylene blue solution was taken in reagent bottle and $0.01 \mathrm{gm}$ of activated carbon was mixed and stirred thoroughly. Sample solution was withdrawn at a predefined interval of time. The solution was centrifuged and carbon particle free solution was placed in a UV vis. Spectrophotometer to determine the absorbance and finally to calculate the adsorbed amount of methylene blue after a specific time. Dye removal percentage was plotted against time.

\section{Results and Discussions}

\subsection{Scanning Electron Microscopy (SEM) Image Analysis}

Scanning electron microscope images of a sample by scanning it with a high-energy beam of electrons. The electrons interact with the atoms those make up the sample producing signals that contain information about the sample's surface topography. In this study SEM images of activated carbons treated with zinc chloride and phosphoric acid were taken. SEM image of activated carbon was taken by Hitachi N-3400 equipment at BCSIR lab, Dhaka. The SEM image of zinc chloride treated activated carbon shows the welldeveloped micro pore structure (Fig. 1). Whereas, the SEM image of activated carbon treated with phosphoric acid shows a well-developed pore structure with comparatively bigger pore than zinc chloride activated carbon (Fig. 2).

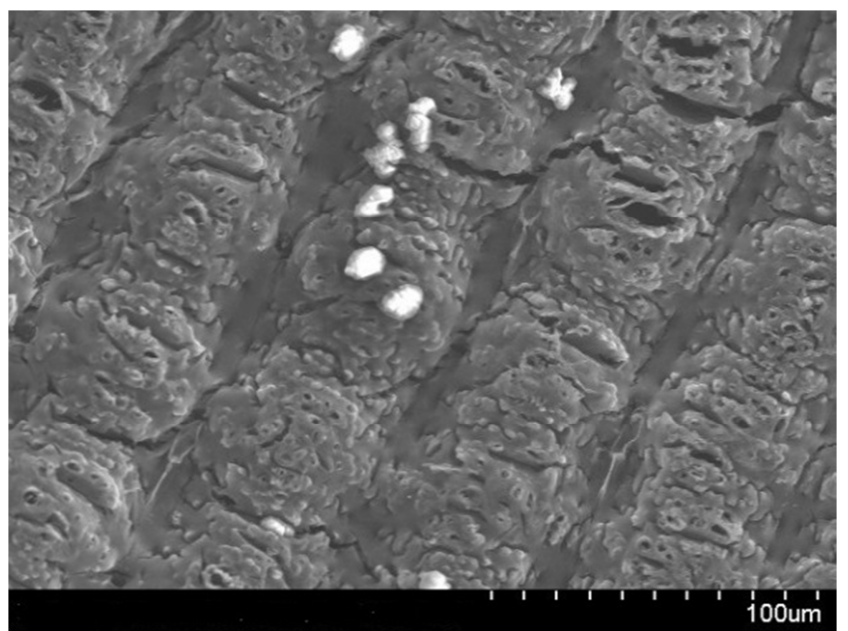

Figure 1. SEM image of activated $\left(\mathrm{ZnCl}_{2}\right)$ rice husk char at $800^{\circ} \mathrm{C}$.

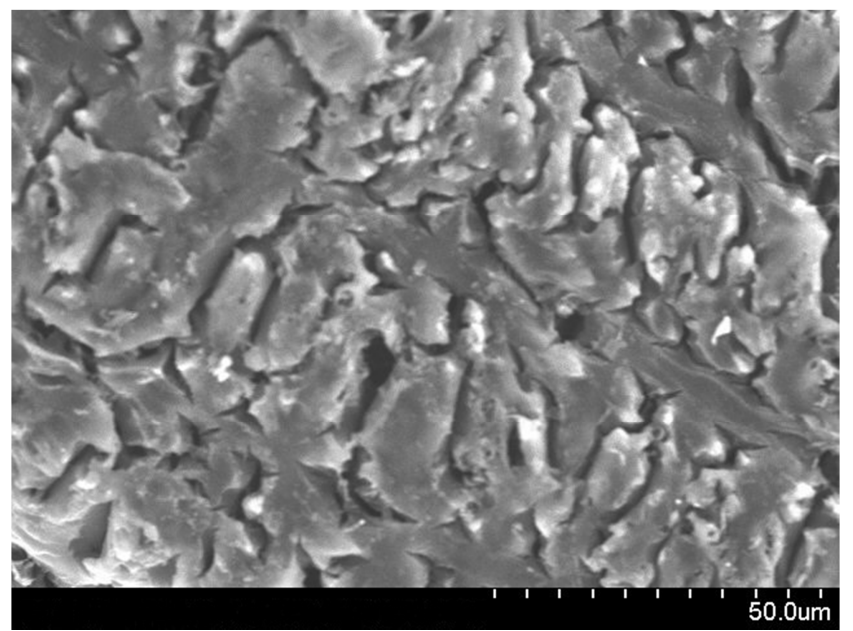

Figure 2. SEM image of activated $\left(\mathrm{H}_{3} \mathrm{PO}_{4}\right)$ rice husk char at $800^{\circ} \mathrm{C}$.

\subsection{Effect of Zinc Chloride and Phosphoric Acid on Surface Area}

Two samples of activated carbon one from zinc chloride treated and another from phosphoric acid treated sample was taken. The surface area of zinc chloride treated sample was found to be $927 \mathrm{~m}^{2} / \mathrm{gm}$ (Fig. 3). The specific surface area of this sample was calculated as $599 \mathrm{~m}^{2} / \mathrm{gm}$ by methylene blue adsorption technique. The difference of the specific surface area due to area coverage by the adsorption of smaller molecule of nitrogen compared to bigger molecule of methylene blue. It reveals that $35 \%$ of surface area accounted by the micro and nano-pore level.

The BET surface of phosphoric acid treated activated carbon was found to be $718 \mathrm{~m}^{2} / \mathrm{gm}$ (Fig. 3). The specific surface area of this sample was calculated as $646 \mathrm{~m}^{2} / \mathrm{gm}$ by the technique of methylene blue adsorption. It reveals that $10 \%$ more surface area was under coverage accounted due to adsorption of smaller molecule of nitrogen at micro and nano-pore level compared to bigger molecule adsorption of methylene blue.

Zinc chloride treated activated carbon showed about 30\% 
higher BET surface area compared with phosphoric acid treated in this study, similar increase in BET surface area by zinc chloride treated over phosphoric acid treated activated carbon from sugarcane bagasse was reported in [35].

In contrast among two samples of activated carbon, zinc chloride treated sample shows less meso-porous area and higher micro and nano porous area compared to phosphoric acid treated activated carbon. This information can help to produce activated carbon at desired level of meso, micro or nano pore depending on the expected use of activated carbon.

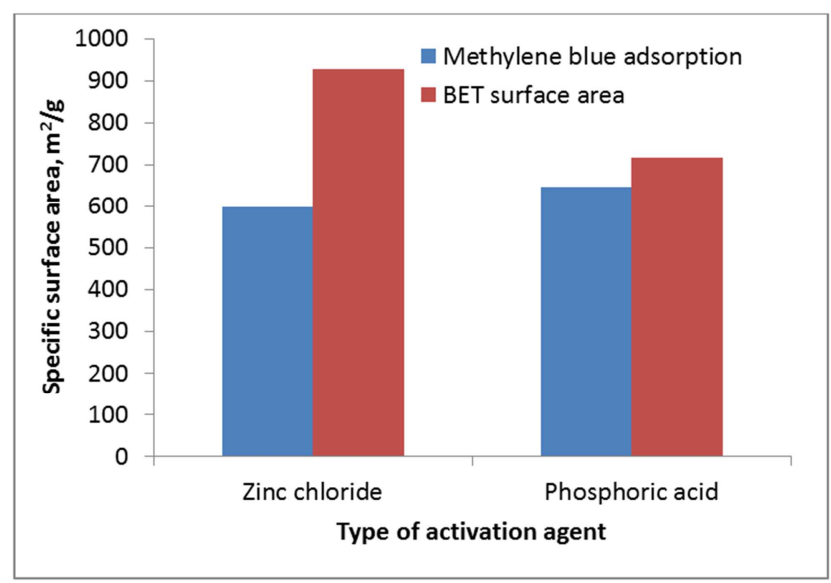

Figure 3. Comparative specific surface area of zinc chloride and phosphoric acid activated carbon.

\subsection{Contact Time Study}

The kinetic curves of activated carbons are shown in Fig. 4. The extent of methylene blue dye removal by activated carbon increased with the increased of contact time. The removal percentage of dye by activated carbon was found to be rapid at the initial period of contact time and then became slower with the increase of contact time. This is due to the strong attractive forces between the dye molecules and the activated carbon. The rate of adsorption varied among the different activated carbon samples. The kinetic curves of activated carbons followed power equation with very good correlation coefficient with the range of 0.91 to 0.99 . The adsorption kinetic curves show that after a minute of contact time percentage of dye removed varied from $24 \%$ to $34 \%$.

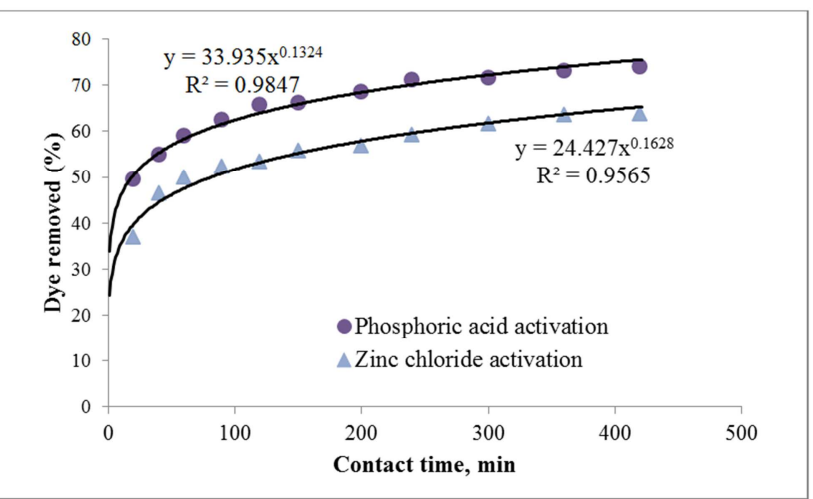

Figure 4. Showing adsorption kinetic study results for phosphoric acid and zinc chloride activated carbons.

\section{Conclusion}

The study clearly expresses the effect of activation agent on pore development in activated carbon. Zinc chloride and phosphoric acid are used as activation agent in this study. The activated carbon evaluation with methylene blue and liquid nitrogen adsorption show different magnitude of specific surface area. Phosphoric acid impregnated activated carbon shows higher specific surface area compared to that of zinc chloride impregnated activated carbon in methylene adsorption test. In contrast zinc chloride shows higher surface area compared to that of phosphoric acid impregnated activated carbon in liquid nitrogen adsorption test. This happened because zinc chloride could develop smaller size pore in higher degree compared phosphoric acid during activation process. Results show that development of pore size is affected by two different agents. From this study it is concluded that the desired size of pores in activated carbon could be achieved for adsorption of species with specific molecular diameter by varying the type of activation agents.

\section{Acknowledgements}

We would like to thank Islamic University of Technology and Chemical Engineering Department, Bangladesh University of Engineering and Technology for their assistance to conduct this study.

\section{References}

[1] Pelekani, C. and V. L. Snoeyink, Competitive adsorption between atrazine and methylene blue on activated carbon: the importance of pore size distribution. Carbon. Vol. 38, No. 10, pp. 1423-1436, 2000.

[2] Pelekani, C. and V. L. Snoeyink, A kinetic and equilibrium study of competitive adsorption between atrazine and Congo red dye on activated carbon: the importance of pore size distribution. Carbon. Vol. 39, No. 1, pp. 25-37, 2001.

[3] Lorenc-Grabowska, E., M. A. Diez, and G. Gryglewicz, Influence of pore size distribution on the adsorption of phenol on PET-based activated carbons. Journal of colloid and interface science. Vol. 469, 205-212, 2016.

[4] Sethia, G. and A. Sayari, Comprehensive study of ultramicroporous nitrogen-doped activated carbon for $\mathrm{CO} 2$ capture. Carbon. Vol. 93, 68-80, 2015.

[5] Sethia, G. and A. Sayari, Activated carbon with optimum pore size distribution for hydrogen storage. Carbon. Vol. 99, 289294, 2016.

[6] Huang, M. C., C. H. Chou, and H. Teng, Pore-size effects on activated-carbon capacities for volatile organic compound adsorption. AIChE journal. Vol. 48, No. 8, pp. 1804-1810, 2002.

[7] Li, L., P. A. Quinlivan, and D. R. U. Knappe, Effects of activated carbon surface chemistry and pore structure on the adsorption of organic contaminants from aqueous solution. Carbon. Vol. 40, No. 12, pp. 2085-2100, 2002. 
[8] Ding, L., V. L. Snoeyink, B. J. Mariñas, Z. Yue, and J. Economy, Effects of powdered activated carbon pore size distribution on the competitive adsorption of aqueous atrazine and natural organic matter. Environmental Science \& Technology. Vol. 42, No. 4, pp. 1227-1231, 2008.

[9] Sevilla, M. and A. B. Fuertes, CO 2 adsorption by activated templated carbons. Journal of colloid and interface science. Vol. 366, No. 1, pp. 147-154, 2012.

[10] Singh, N. and C. Balomajumder, Simultaneous removal of phenol and cyanide from aqueous solution by adsorption onto surface modified activated carbon prepared from coconut shell. Journal of Water Process Engineering. Vol. 9, 233-245, 2016.

[11] Ojo, O. O. Effect of base material on the pore size distribution and surface area of activated carbon. in Advanced Materials Research, Trans Tech Publ, 2009.

[12] Pelekani, C. and V. L. Snoeyink, Competitive adsorption in natural water: role of activated carbon pore size. Water Research. Vol. 33, No. 5, pp. 1209-1219, 1999.

[13] Lee, S. Y. and S. J. Park, Determination of the optimal pore size for improved CO 2 adsorption in activated carbon fibers. Journal of colloid and interface science. Vol. 389, No. 1, pp. 230-235, 2013.

[14] Laine, J. and A. Calafat, Preparation and characterization of activated carbons from coconut shell impregnated with phosphoric acid. Carbon. Vol. 27, No. 2, pp. 191-195, 1989.

[15] Girgis, B. S. and M. F. Ishak, Activated carbon from cotton stalks by impregnation with phosphoric acid. Materials Letters. Vol. 39, No. 2, pp. 107-114, 1999.

[16] Ahmedna, M., W. E. Marshall, and R. M. Rao, Surface properties of granular activated carbons from agricultural byproducts and their effects on raw sugar decolorization. Bioresource technology. Vol. 71, No. 2, pp. 103-112, 2000.

[17] Kadirvelu, K., M. Kavipriya, C. Karthika, M. Radhika, N. Vennilamani, and S. Pattabhi, Utilization of various agricultural wastes for activated carbon preparation and application for the removal of dyes and metal ions from aqueous solutions. Bioresource technology. Vol. 87, No. 1, pp. 129-132, 2003.

[18] Narmata, D. and A. Manzoor, Dye adsorption by a new low cost material Congo red. Ind J Environ Protec. Vol. 13, 570576, 1993.

[19] Wigmans, T., Industrial aspects of production and use of activated carbons. Carbon. Vol. 27, No. 1, pp. 13-22, 1989.

[20] Ibarra, J. V., R. Moliner, and J. M. Palacios, Catalytic effects of zinc chloride in the pyrolysis of spanish high sulphur coals. Fuel. Vol. 70, No. 6, pp. 727-732, 1991.

[21] Munoz-Guillena, M. J., M. J. Illán-Gómez, J. M. MartinMartinez, A. Linares-Solano, and C. Salinas-Martinez de Lecea, Activated carbons from Spanish coals. 1. Two-stage carbon dioxide activation. Energy \& fuels. Vol. 6, No. 1, pp. 9$15,1992$.
[22] Jagtoyen, M. and F. Derbyshire, Some considerations of the origins of porosity in carbons from chemically activated wood. Carbon. Vol. 31, No. 7, pp. 1185-1192, 1993.

[23] Teng, H. and H. C. Lin, Activated carbon production from low ash subbituminous coal with $\mathrm{CO}_{2}$ activation. AIChE Journal. Vol. 44, No. 5, pp. 1170-1177, 1998.

[24] Dubinin, M. M., Fundamentals of the theory of adsorption in micropores of carbon adsorbents: characteristics of their adsorption properties and microporous structures. Carbon. Vol. 27, No. 3, pp. 457-467, 1989.

[25] Sing, K. S. W., D. H. Everett, R. A. W. Haul, L. Moscou, R. A. Pierotti, J. Rouquerol, and T. Siemieniewska, Reporting physisorption data for gas/solid systems with special reference to the determination of surface area and porosity (Recommendations 1984). Pure and applied chemistry. Vol. 57, No. 4, pp. 603-619, 1985.

[26] Guettai, N. and H. A. Amar, Photocatalytic oxidation of methyl orange in presence of titanium dioxide in aqueous suspension. Part I: Parametric study. Desalination. Vol. 185, No. 1, pp. 427-437, 2005.

[27] Rys, P. and H. Zollinger, Fundamentals of the Chemistry and Application of Dyes, Wiley-Interscience New York, 1972.

[28] Zollinger, H., Color chemistry: syntheses, properties, and applications of organic dyes and pigments, Wiley-VCH Weinheim, 2003.

[29] Dai, S., W. Song, Y. Zhuang, and H. Yan. Biotechnical treatment of wastewater containing azo dyes. in Proceedings of the 4th Mainland-Taiwan Environmental Technology Seminar, 1996.

[30] Dai, S., Y. Zhuang, L. Chen, and L. Chen, Study on the relationship between structure of synthetic organic chemicals and their biodegradability. Environ. Chem. Vol. 14, 354-367, 1995.

[31] Chung, K., G. E. Fulk, and A. W. Andrews, Mutagenicity testing of some commonly used dyes. Applied and Environmental Microbiology. Vol. 42, No. 4, pp. 641-648, 1981.

[32] Ahiduzzaman, M. and A. S. Islam, Preparation of porous biochar and activated carbon from rice husk by leaching ash and chemical activation. SpringerPlus. Vol. 5, No. 1, pp. 1248, 2016.

[33] Ahiduzzaman, M., Studies and investigation on extraction of energy and value-added product from rice husk, Ph.D. Thesis in Mechanical and Chemical Engineering Department, Islamic University of Technology, Gazipur, Bangladesh, 2011.

[34] Brunauer, S., P. H. Emmett, and E. Teller, Adsorption of gases in multimolecular layers. Journal of the American chemical society. Vol. 60, No. 2, pp. 309-319, 1938.

[35] Liou, T. H., Development of mesoporous structure and high adsorption capacity of biomass-based activated carbon by phosphoric acid and zinc chloride activation. Chemical Engineering Journal. Vol. 158, No. 2, pp. 129-142, 2010. 